\title{
Correlation between Thrombolysis in Myocardial Infarction and The Global Registry of Acute Coronary Syndromes Risk Scores and Severity of Coronary Artery Disease in Patients with Non-ST Elevation Acute Coronary Syndrome
}

Mahmoud El-Sayed ${ }^{1 *}$, Abdelrahman Aly², Ashraf Abotaleb ${ }^{3}$, Ahmed Gaafar ${ }^{4}$, Mohammed Sarhan ${ }^{2}$, Abdelrahman Elbokary ${ }^{5}$, Monir Osman $^{2}$

${ }^{1}$ Department of Cardiology, Mabaret Misr Alqadema Hospital, ${ }^{2}$ Department of Cardiology, ${ }^{3}$ Department of Clinical Pathology, Faculty of Medicine, Al-Azhar University, ${ }^{4}$ Department of Cardiology, Faculty of Medicine,

Helwan University, ${ }^{5}$ Department of Cardiology, National Heart Institute, Cairo, Egypt

*Corresponds to: Mahmoud A. El-Sayed, Tel: +20-(0)1091294954, E-mail: taweel10@ gmail.com

\begin{abstract}
Background: the prognosis of non-ST elevation acute coronary syndrome (NSTEACS) patients is frequently done by using thrombolysis in myocardial infarction (TIMI) and global registry of acute coronary events (GRACE) risk scores. Only few studies were done for prediction ability of the scores with coronary artery disease. Methods: this prospective cross-sectional study included 100 patients was conducted at Mabaret Misr Alqadema and Al-Azhar University Hospitals from May 2017 till September 2018. We calculated the TIMI and the GRACE risk scores for all patients on admission then patients had coronary angiography to detect the extent of the coronary artery disease (CAD). We assessed the severity of CAD by using Gensini score and vessel score. Results: the TIMI and GRACE scores have an acceptable predictive value in identifying the extent of the CAD. A TIMI score $\geq 3$ and GRACE score $\geq 102$ was significantly associated with 3 vessel disease and left main disease ( $p<0.014$ for TIMI and $p<0.007$ for GRACE). On comparison of the two risk scores, the discriminatory accuracy of the GRACE score was nonsignificantly superior to the TIMI score in predicting 3 vessel and left main (LM) diseases but the combination of both scores has a higher accuracy $(\mathrm{p}<0.006)$. Conclusions: the CAD is more extensive by coronary angiography in patients with NSTEACS who had higher TIMI or GRACE risk scores, as they have a good predictive value. However, when both compared, the GRACE score has a non-statistically significant superiority with multivessel and LM disease, and combination of both scores has a higher accuracy.
\end{abstract}

Keywords: NSEMI-ACS, TIMI risk score, GRACE risk score, Gensini risk score, CAD.

\section{INTRODUCTION}

Globally, ischemic heart disease remains the number one cause of morality ${ }^{(\mathbf{1})}$. NSTEACS is more frequent than STEACS with annual incidence is about 3 per 1000 inhabitants ${ }^{(2)}$, with similar mortality as STEMI at 6 months $^{(3)}$ and higher with a two-fold difference at 4 years $^{(4)}$.

Risk models as GRACE and TIMI scores predict a probability for adverse outcomes based on combinations of clinical, ECG, and laboratory data available at presentation assist in identifying patients at risk for recurrent ischemia and death events ${ }^{(5,6)}$. the GRACE and TIMI RSs are the most widely used ${ }^{(7)}$, GRACE is more accurate than TIMI score but it is more complex ${ }^{(\mathbf{8}, \mathbf{9})}$.

\section{PATIENTS AND METHODS}

Study population and method: This was a prospective observational study, which involved 100 NSTEMI patients, during the period from May 2017 till September 2018. After approval of the ethical committee of the faculty and after individual written consent, patients had coronary angiography then we divided the study population into 2 groups: Single or two-vessel CAD group and 3 vessel or LM
CAD group then compared both groups against TIMI and GRACE risk scores.

We excluded from the study patients who had previous coronary artery bypass surgery, myocardial infarction, or previous percutaneous coronary intervention (PCI), patients whose systolic blood pressure (SBP) was more than $180 \mathrm{~mm} \mathrm{Hg}$ or diastolic blood pressure (DBP) was more than $110 \mathrm{~mm} \mathrm{Hg}$ and patients with a missing data for calculating the GRACE RS and TIMI RS.

For each enrolled patient, we collected the following data; clinical data (full history, cardiac risk factors and clinical examination), ECG, conventional echocardiographic, laboratory data (CBC, serum creatinine, $\mathrm{CK}-\mathrm{MB}$, troponin, coagulation profile and lipid profile) and CA data.

\section{Calculation of the GRACE and the TIMI risk scores}

GRACE risk score (GRS); It was calculated by using specific variables (age, heart rate, SBP, creatinine, Killip class, elevated cardiac markers, ST-segment deviation, cardiac arrest at admission) gathered at admission, and accordingly patients were divided into low (GRS <108), intermediate (GRS 109-140) and high (GRS >141) risk groups. 
TIMI risk score (TRS); at admission the data was gathered: Age $\geq 65$, aspirin use in the last 7 days, at least 2 angina episodes within the last $24 \mathrm{hrs}$., ST segment deviation of $0.5 \mathrm{~mm}$ or more on admission ECG, elevated cardiac biomarkers, at least 3 risk factors for CAD and known coronary artery disease (CAD) (coronary stenosis $\geq 50 \%$ ), scored 1 point for each $^{(\mathbf{1 0})}$. Based on TRS values, the study population was divided into Low (TRS 0-2), intermediate (TRS 3-4), and high-risk Groups (TRS 5-7).

Coronary arteries anatomies were assessed by cardiac catheterization, a vessel score according to the presence of vessel disease $>70 \%$ in the major epicardial vessels (LAD, LCX and RCA, a large diagonal branch or obtuse marginal also considered in the major epicardial vessels) or presence of left main disease $>50 \%$. The extent of CAD was defined as single vessel disease, two vessel disease or three vessel disease CAD.

A quantitative analysis was performed by using the Gensini score, a score that depends on the lesion stenosis and area supplied by coronary artery, each gets a score, where stenosis diameter $(0-25 \%=1$; $26 \%-50 \%=2 ; 51 \%-75 \%=4 ; 76 \%-90 \%=8 ; 91 \%$ $99 \%=16 ; 100 \%=32$ points $)$ and the vessel scored according to anatomical importance (ranging from 0.5 to 5), then multiplied by each other, and all are summed to get a final score. ${ }^{(11)}$

Statistical analysis; We analyzed data using Statistical Program for Social Science (SPSS) version 23, NCSS version 12 and MedCalc version 15.4.

Quantitative data were clarified by mean \pm standard deviation (SD). While qualitative data were cleared using the chi-square test, or Fisher's exact test when the chi-square test was not appropriate. The normality of distribution of quantitative variables was assessed by calculating kurtosis and skewness coefficients and by the Kolmogorov-Smirnov test. Student's t test was the test of comparisons for normal distributions, otherwise the Mann-Whitney test was used.

Receiver operating characteristic (ROC) curves were used to determine the predictive accuracy of the risk scores regarding obstructive and severe CAD (presence of LM or $3 \mathrm{VD}$ ). Criteria to qualify for AUC were as follows: $0.90-1=$ excellent, $0.80-0.90=$ good, $0.70-0.80$ = fair; $0.60-0.70=$ poor; and 0.50-0.6 $=$ fail. The optimal cutoff point was established at point of maximum accuracy.

\section{RESULTS}

The mean age of studied population was $57.4 \pm 7.8$ years (ranged from 38-79 years). Males represented $70 \%$ (70 patients) of the study population while females represented 30\% (30 patients). Forty four percent (44 patients) were hypertensive while fifty two percent (52 patients) were diabetic and forty seven percent (47 patients) were smokers. (Table 1).

Coronary angiography showed that forty nine percent (49 patients) had a single vessel disease, twenty six percent (26 patients) had two vessels disease and twenty five percent (25 patients) had LM or three vessels disease. The mean Gensini score was $38.7 \pm 35.3$ (ranged from $0-178$ ).

The TIMI risk score among the study population; the study population mean TIMI score was $2.6 \pm 1.2$ ranging from (1-6). Fifty patients $(50 \%)$ had a low TIMI score (0-2), forty two patients $(42 \%)$ had an intermediate TIMI risk score (3-4) and eight patients (8\%) had high TIMI risk score (5-6).

The GRACE risk score among the study population; the mean GRACE risk score was $96.5 \pm$ 20.4 ranging from $(46-156)$. Seventy one patients (71\%) of the study population had a low GRACE risk score $(\leq 108)$, twenty six patients $(26 \%)$ had an intermediate GRACE risk score $(109-140)$ and three patients (3\%) had high GRACE risk score $(\geq 141)$.

We divided the study population into two groups LM or 3 vessel group and Single or two vessels group.

There were significant differences between low risk, intermediate risk and high risk TIMI scores as regard Gensini score $(28.8 \pm 29$ vs. $42.8 \pm 35.9$ vs. $81.0 \pm 33.8$ respectively, $\mathrm{p}$ value $<0.001$ ) with significant positive correlation between both scores $(\mathrm{r}$ 0.374 , $\mathrm{p}$ value $<0.001$ ). (Figure 1 )

There were significantly differences between low risk, intermediate risk and high risk GRACE scores as regard Gensini score $(30.9 \pm 31.2$ vs. $54.8 \pm 36.4$ vs. $87.3 \pm 37.8$ respectively, $\mathrm{p}$ value $<0.001$ ) with significant positive correlation between both scores $(\mathrm{r}$ $0.408, \mathrm{p}$ value $<0.001$ ). (Figure 2)

The LM or three vessels disease group had higher TIMI risk score ( $3.2 \pm 1.4$ vs. $2.5 \pm 1.0$, p value 0.014$)$ (Table 2), GRACE Risk score (105.4 \pm 23.8 vs. 93.5 \pm 18.4 , p value 0.011 ) (Table 3 ) and Gensini score $(82.9 \pm 41.9$ vs. $24.1 \pm 14.1$, p-value 0.001$)$.

ROC curve analysis for different scores in predicting LM or three-vessel disease: In our study the TIMI risk score at value 3 showed moderate sensitivity (72\%) and low specificity (57.3\%) and good negative predictive value of $(86 \%)$ while GRACE risk score showed moderate specificity (62\%) and sensitivity (68\%) and good negative predictive value (NPV) of ( $85.5 \%)$. The combination of both scores had a moderate sensitivity (68\%), good specificity $(62.7 \%)$, moderate positive predictive value (PPV) (56.7\%) and good negative predictive value $(88.6 \%)$ so the combination of both scores showed higher accuracy as it had best PPV (56.7\%) and specificity (82.7\%) with good NPV (88.6\%) and moderate sensitivity (68\%) (Table 4 and Figure 3 ). 
Table (1): Demographic data of study population

\begin{tabular}{|c|c|}
\hline Demographic data Count (\%) & All patients $100(100 \%)$ \\
\hline \multicolumn{2}{|c|}{ Age (years) } \\
\hline Mean $\pm S D$ & $57.4 \pm 7.8$ \\
\hline Median (Range) & $57(38-79)$ \\
\hline \multicolumn{2}{|c|}{ Gender } \\
\hline Male & $70(70 \%)$ \\
\hline Female & $30(30 \%)$ \\
\hline \multicolumn{2}{|c|}{ Risk factors } \\
\hline$H T N$ & $44(44 \%)$ \\
\hline$D M$ & $52(52 \%)$ \\
\hline Smoking & $47(47 \%)$ \\
\hline Hypercholesterolemia & $39(39 \%)$ \\
\hline Family history of IHD & $16(16 \%)$ \\
\hline Known CAD & $2(2 \%)$ \\
\hline \multicolumn{2}{|c|}{ Number of risk factors } \\
\hline Less than 3 CAD risk factors & $75(75 \%)$ \\
\hline Three or more CAD risk factors & $25(25 \%)$ \\
\hline
\end{tabular}

Table (2): Comparison between the studied groups regarding the TIMI risk items and score

\begin{tabular}{|c|c|c|c|c|}
\hline TIMI risk items and score & $\begin{array}{l}\text { LM or three-vessel } \\
\text { disease }\end{array}$ & $\begin{array}{l}\text { Single or two-vessel } \\
\text { disease }\end{array}$ & \multirow{2}{*}{ Test } & \multirow{2}{*}{$\begin{array}{c}\text { P-value } \\
\text { (Sig.) }\end{array}$} \\
\hline Count (\%) & $25(25 \%)$ & $75(75 \%)$ & & \\
\hline \multicolumn{5}{|c|}{ Item } \\
\hline Age $\geq 65$ years & $18(72 \%)$ & $65(86.7 \%)$ & $2.858+\mathbf{F}$ & $0.123(\mathrm{NS})$ \\
\hline $\begin{array}{l}\text { Three or more CAD risk } \\
\text { factors }\end{array}$ & $11(44 \%)$ & $14(18.7 \%)$ & $6.418 \div$ & $0.011(\mathrm{~S})$ \\
\hline Known $C A D$ & $1(4 \%)$ & $1(1.3 \%)$ & $0.680 \div \mathbf{F}$ & $0.439(\mathrm{NS})$ \\
\hline ASA use in past 7 days & $8(32 \%)$ & $13(17.3 \%)$ & $2.431 \ddagger$ & $0.119(\mathrm{NS})$ \\
\hline $\begin{array}{c}\text { Severe angina }(\geq 2 \text { episodes } \\
\text { in } 24 \text { hours) }\end{array}$ & $14(56 \%)$ & $41(54.7 \%)$ & $0.013 \ddagger$ & $0.908(\mathrm{NS})$ \\
\hline ECG changes & $22(88 \%)$ & $63(84 \%)$ & $0.235 \div \mathrm{F}$ & $0.755(\mathrm{NS})$ \\
\hline Positive cardiac biomarkers & $23(92 \%)$ & $67(89.3 \%)$ & $0.148 \dagger^{\mathrm{F}}$ & $1.00(\mathrm{NS})$ \\
\hline \multicolumn{5}{|c|}{ TIMI score } \\
\hline Mean $\pm S D$ & $3.2 \pm 1.4$ & $2.5 \pm 1.0$ & \multirow{2}{*}{$2.460 \bullet$} & \multirow{2}{*}{$0.014(\mathrm{~S})$} \\
\hline Median (Range) & $3(1-5)$ & $2(1-6)$ & & \\
\hline \multicolumn{5}{|c|}{ TIMI risk stratification } \\
\hline $\operatorname{Low}(\leq 2)$ & $7(28 \%)$ & $43(57.3 \%)$ & \multirow{3}{*}{$10.02 \ddagger$} & \multirow{3}{*}{$0.007(\mathrm{~S})$} \\
\hline Intermediate $(3-4)$ & $13(52 \%)$ & $29(38.7 \%)$ & & \\
\hline $\operatorname{High}(\geq 5)$ & $5(20 \%)$ & $3(4 \%)$ & & \\
\hline \multicolumn{5}{|c|}{$\begin{array}{l}\text { * Independent samples Student's t-test. } \quad \text { Mann Whitney U test. } \\
+ \text { Chi-square test. } \quad \text { F Fisher's Exact test. } \quad p<0.05 \text { is sigr }\end{array}$} \\
\hline
\end{tabular}

(The meaning of these signs " $+\mathrm{F}$ " should be written) 
Table (3): Comparison between the studied groups regarding the GRACE risk items and score

\begin{tabular}{|c|c|c|c|c|}
\hline GRACE risk items and score & $\begin{array}{l}\text { LM or three-vessel } \\
\text { disease }\end{array}$ & $\begin{array}{c}\text { Single or two-vessel } \\
\text { CAD }\end{array}$ & \multirow{2}{*}{ Test } & \multirow{2}{*}{$\begin{array}{l}\text { P-value } \\
\text { (Sig.) }\end{array}$} \\
\hline Count (\%) & $25(25 \%)$ & $75(75 \%)$ & & \\
\hline \multicolumn{5}{|c|}{ Age (years) } \\
\hline Mean $\pm S D$ & $59.6 \pm 8.4$ & $56.7 \pm 7.4$ & \multirow{2}{*}{$1.668 *$} & \multirow{2}{*}{$0.098(\mathrm{NS})$} \\
\hline Median (Range) & $59(42-79)$ & $57(38-74)$ & & \\
\hline \multicolumn{5}{|c|}{ Pulse (beat/min) } \\
\hline Mean $\pm S D$ & $86.8 \pm 10.2$ & $84.7 \pm 9.6$ & \multirow{2}{*}{$0.961 *$} & \multirow{2}{*}{$0.339(\mathrm{NS})$} \\
\hline Median (Range) & $89(65-110)$ & $85(65-110)$ & & \\
\hline \multicolumn{5}{|c|}{$\mathrm{SBP}(\mathrm{mmHg})$} \\
\hline Mean $\pm S D$ & $143.6 \pm 18.9$ & $134.9 \pm 21.4$ & \multirow{2}{*}{$1.647 \bullet$} & \multirow{2}{*}{$0.100(\mathrm{NS})$} \\
\hline Median (Range) & $140(110-180)$ & $140(90-180)$ & & \\
\hline \multicolumn{5}{|c|}{ Creatinine $(\mathrm{mg} / \mathrm{dL})$} \\
\hline Mean $\pm S D$ & $1.12 \pm 0.27$ & $1.04 \pm 0.22$ & \multirow{2}{*}{$1.549 \bullet$} & \multirow{2}{*}{$0.121(\mathrm{NS})$} \\
\hline Median (Range) & $1.1(0.7-1.8)$ & $1.0(0.6-1.6)$ & & \\
\hline \multicolumn{5}{|c|}{ Killip class } \\
\hline Class I & $19(76 \%)$ & $73(97.3 \%)$ & \multirow{3}{*}{$12.483 \ddagger$} & \multirow{3}{*}{$0.002(\mathrm{~S})$} \\
\hline Class II & $5(20 \%)$ & $1(1.3 \%)$ & & \\
\hline Class III & $1(4 \%)$ & $1(1.3 \%)$ & & \\
\hline ST-segment deviation on ECG & $22(88 \%)$ & $63(84 \%)$ & $0.235 \div \mathbf{F}$ & $0.755(\mathrm{NS})$ \\
\hline Abnormal cardiac enzymes & $23(92 \%)$ & $67(89.3 \%)$ & $0.148 \div \mathbf{F}$ & $1.00(\mathrm{NS})$ \\
\hline Cardiac arrest on admission & $0(0 \%)$ & $0(0 \%)$ & - & - \\
\hline \multicolumn{5}{|c|}{ GRACE score } \\
\hline Mean $\pm S D$ & $105.4 \pm 23.8$ & $93.5 \pm 18.4$ & \multirow{2}{*}{$2.579 *$} & \multirow{2}{*}{$0.011(\mathrm{~S})$} \\
\hline Median (Range) & $109(57-156)$ & $94(46-143)$ & & \\
\hline \multicolumn{5}{|c|}{ GRACE risk stratification } \\
\hline $\operatorname{Low}(\leq 108)$ & $12(48 \%)$ & $59(78.7 \%)$ & \multirow{3}{*}{$9.415 \ddagger$} & \multirow{3}{*}{$0.009(\mathrm{~S})$} \\
\hline Intermediate $(109-140)$ & $11(44 \%)$ & $15(20 \%)$ & & \\
\hline $\operatorname{High}(\geq 141)$ & $2(8 \%)$ & $1(1.3 \%)$ & & \\
\hline $\begin{array}{l}\text { * Independent samples Student' } \\
+ \text { Chi-square test. } \$ \quad \text { F Fis }\end{array}$ & $\begin{array}{l}\text { t. }- \text { Mann Whitne } \\
\text { Exact test. } \quad \mathrm{p}<0\end{array}$ & $\begin{array}{l}\text { st. } \\
\text { significant. }\end{array}$ & & \\
\hline
\end{tabular}

Table (4): The predictive performance of different scores; ROC curve analysis

\begin{tabular}{|c|c|c|c|c|c|c|c|}
\hline $\begin{array}{l}\text { Cut-off } \\
\text { values }\end{array}$ & $\begin{array}{c}\text { SN \% } \\
(\mathbf{9 5 \%} \mathrm{CI})\end{array}$ & $\begin{array}{c}\text { SP \% } \\
(\mathbf{9 5 \%} \mathrm{CI})\end{array}$ & $\begin{array}{c}\text { PPV \% } \\
(\mathbf{9 5 \%} \text { CI })\end{array}$ & $\begin{array}{l}\text { NPV \% } \\
(\mathbf{9 5 \%} \mathrm{CI})\end{array}$ & \begin{tabular}{|c} 
AUROC \\
$(95 \%$ \\
CI $)$ \\
\end{tabular} & $\mathrm{Z}$ statistic & $\begin{array}{c}\text { P-value } \\
\text { (Sig.) }\end{array}$ \\
\hline $\begin{array}{l}\text { TIMI score } \\
\quad \geq 3\end{array}$ & $\begin{array}{c}72 \% \\
(50.6-87.9)\end{array}$ & $\begin{array}{c}57.3 \% \\
(45.4-68.7)\end{array}$ & $\begin{array}{c}36 \% \\
(22.9-50.8)\end{array}$ & $\begin{array}{c}86 \% \\
(73.3-94.2)\end{array}$ & $\begin{array}{c}0.659 \\
(0.494- \\
0.778) \\
\end{array}$ & 2.203 & $\begin{array}{l}\mathbf{0 . 0 1 4} \\
(\mathrm{S})\end{array}$ \\
\hline $\begin{array}{c}\text { GRACE } \\
\text { score } \geq 102\end{array}$ & $\begin{array}{c}68 \% \\
(46.5-85.1)\end{array}$ & $\begin{array}{c}62.7 \% \\
(50.7-73.6)\end{array}$ & $\begin{array}{c}37.8 \% \\
(23.8-53.5)\end{array}$ & $\begin{array}{c}85.5 \% \\
(73.3-93.5)\end{array}$ & $\begin{array}{c}0.672 \\
(0.511- \\
0.787)\end{array}$ & 2.459 & $\begin{array}{c}\mathbf{0 . 0 0 7} \\
(\mathbf{S})\end{array}$ \\
\hline $\begin{array}{l}\text { TIMI with } \\
\text { GRACE }\end{array}$ & $\begin{array}{c}68 \% \\
(46.5-85.1)\end{array}$ & $\begin{array}{c}82.7 \% \\
(\mathbf{7 2 . 2}-\mathbf{9 0 . 4})\end{array}$ & $\begin{array}{c}56.7 \% \\
(37.4-74.5)\end{array}$ & $\begin{array}{c}88.6 \% \\
(78.7-94.9)\end{array}$ & $\begin{array}{c}0.684 \\
(0.511- \\
0.803)\end{array}$ & 2.491 & $\begin{array}{l}\mathbf{0 . 0 0 6} \\
(\mathrm{S})\end{array}$ \\
\hline
\end{tabular}




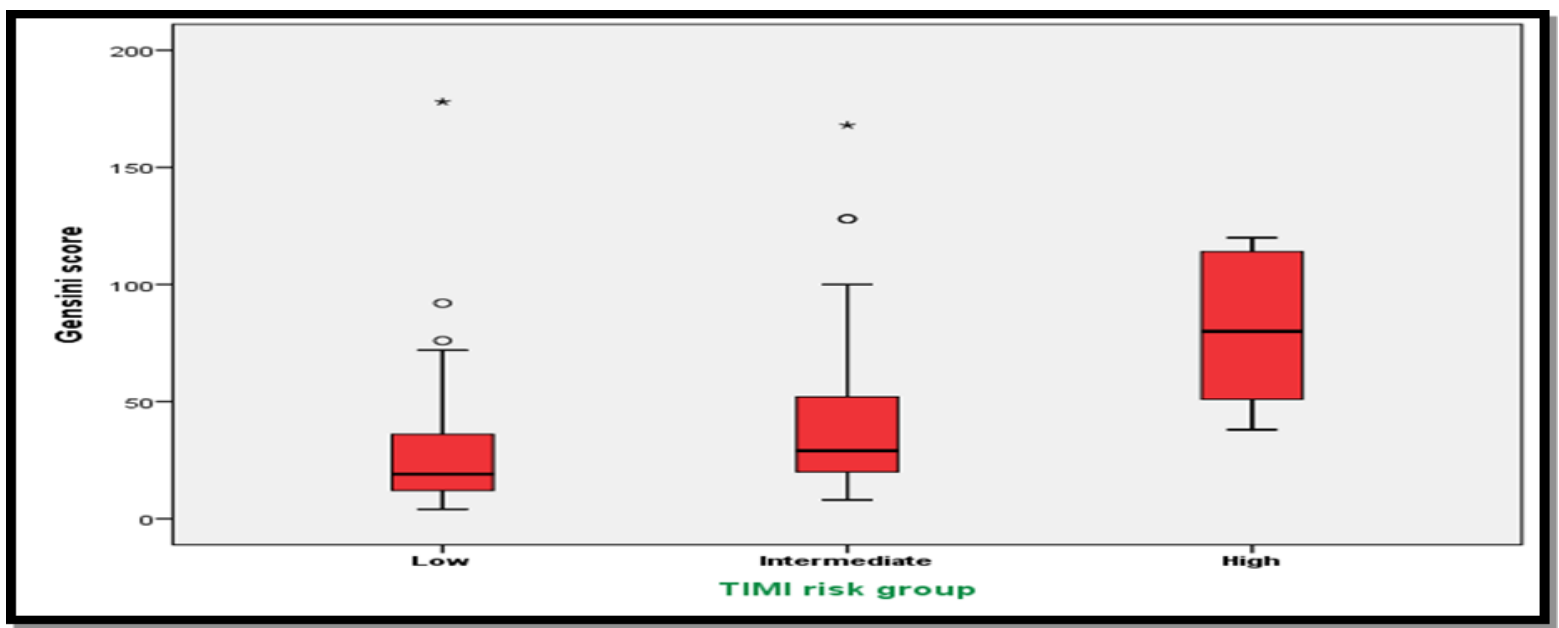

Figure (1): Comparison of TIMI risk score and Gensini score

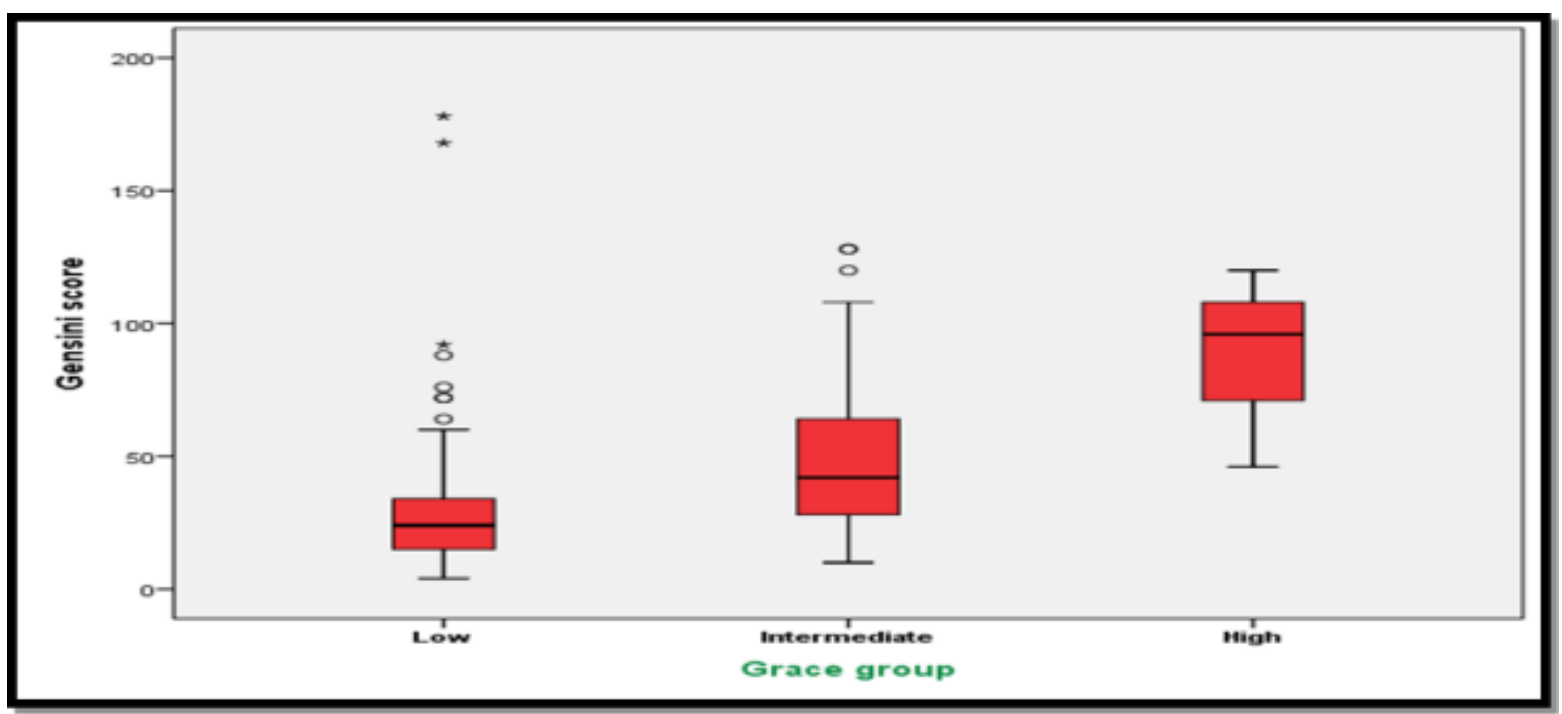

Figure (2): Comparison between the GRACE risk groups regarding Gensini score

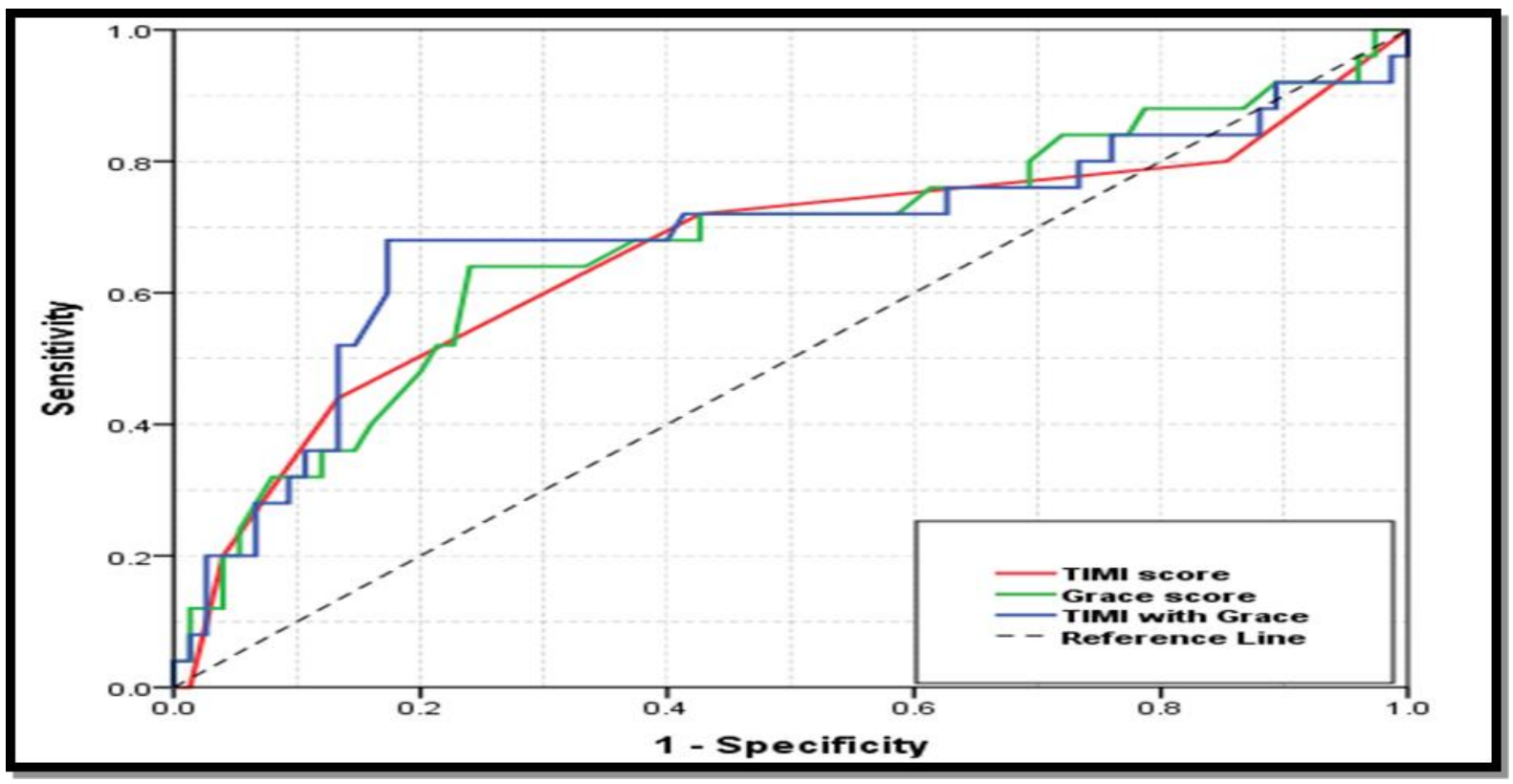

Figure (3): ROC curve analysis for different scores in predicting LM or three-vessel disease 


\section{DISCUSSION}

The relationship between $\mathrm{CAD}$ by coronary angiography, short- and long-term events in ACS patients was established in many studies. So, we tried to find the correlations between prognostic scores and the extent of angiographic disease, and also tried to determine cutoff values of TIMI and GRACE scores that could predict high risk CAD. The target is to avoid an invasive strategy below this cutoff or, conversely, to consider a more aggressive approach for patients whose prognostic score indicates severe angiographic disease.

As regard TIMI score 50 percent of the study population had a low TIMI, forty two percent had an intermediate TIMI risk score and five percent had high TIMI risk score. We found similar pattern of distribution for GRACE risk score where seventy one percent of the study population had a low GRACE risk score, twenty six percent had an intermediate GRACE risk score and three percent had high GRACE risk score, this correlation was demonstrated by Santos et al. ${ }^{(12)}$ who found that coronary lesions more than $50 \%$ is correlated to risk scores positively (TIMI risk score $\mathrm{r}=0.363$ ( $\mathrm{p}<0.0001$ ); hospital GRACE score $\mathrm{r}=0.255(\mathrm{p}<0.0001)$; and GRACE score in six months $r=0.209(p<0.0001))$.

We used Gensini score as it is rapid and easy score for assessment of severity of CAD. We found good correlation between Gensini RS and TMI RS which was revealed in study done by Iscanli et al. ${ }^{(13)}$ which enrolled 165 NSTEMI-ACS patients where they found moderate correlation between TIMI and Gensini scores, that patients at high risk according to either GRACE or TIMI, have a higher Gensini score, and more associated with LM or 3VD.

In our study we found that GRACE and TIMI have a significant association with LM or 3 vessel disease with a higher non-significant association with GRACE, where a GRACE $\geq 102$ and TIMI $\geq 3$ was more associated with 3 vessel disease or LM disease (AUROC $0.672 \mathrm{P} 0.007$ for GRACE and AUROC $0.659 \mathrm{P} 0.014$ for TIMI).

We assessed a combined TIMI and GRACE risk scores for prediction of 3 vessels disease or LM disease using ROC curve and we found that combined approach had better accuracy where sensitivity (68\%), specificity $(62.7 \%)$, positive predictive value $(56.7 \%)$ and negative predictive value $(88.6 \%)$ but we didn't find other studies with this combined approach to compare our results with it.

In a study by Mahmood et al. ${ }^{(\mathbf{1 4 )}}$ a cohort of 406 patients with NSTEACS, showed that on admission, a TIMI score >4 and GRACE score >133 were significantly correlated with three vessel disease and left main disease, while TIMI score $\leq 4$ and GRACE score $\leq 133$ were correlated with non-obstructive
CAD $(p<0.01)$. However that GRACE score was more accurate depending on the angiographic data.

Khandelwal et $\boldsymbol{a l} .{ }^{(15)}$ in their study found that the GRACE correlates moderately with modified Gensini Score $(\mathrm{r}=0.3)$, while the correlation was weak with the PURSUIT $(r=0.274)$ and TIMI scores $(\mathrm{r}=0.166)$.

Barbosa et al. ${ }^{(16)}$ found in patients with ACS the GENSINI score had a positive correlation but weak association with the GRACE $(\mathrm{p}=0.017),(\mathrm{r}=0.23)$ and TIMI $(\mathrm{p}=0.02),(\mathrm{r}=0.27)$ scores. The GRACE score failed to predict obstructive coronary disease (area under the ROC curve $=0.57 ; 95 \% \mathrm{CI}=0.46$ 0.69 ), and failed also to predict severe coronary disease $(\mathrm{ROC}=0.59 ; 95 \% \mathrm{CI}=0.480 .70)$. The TIMI score had small prediction for coronary disease (ROC $=0.65 ; 95 \% \mathrm{CI}=0.550 .76)$ and for severe coronary disease $(\mathrm{ROC}=0.66 ; 95 \% \mathrm{CI}=0.56 \quad 0.76)$. They deduced that a positive association between the TIMI or GRACE scores and the extension of coronary artery disease in patients with ACS is present, but not enough to be a good predictors of coronary angiography results.

\section{CONCLUSION}

In NSTEACS patients who had coronary angiography, both TIMI and GRACE risk scores have a good value in CAD prediction. However, when both compared, the GRACE score has a non-statistically significant superiority with multivessel and LM disease, and combination of both scores has a higher accuracy.

\section{REFERENCES}

1. Lozano R, Naghavi M, Foreman K et al. (2012): Global and regional mortality from 235 causes of death for 20 age groups in 1990 and 2010: a systematic analysis for the Global Burden of Disease Study 2010. Lancet, 380(9859):2095-128.

2. Yeh RW, Sidney S, Chandra M et al. (2010): Population trends in the incidence and outcomes of acute myocardial infarction. N Engl J Med., 2362(23):2155-65.

3. Mandelzweig L, Battler A, Boyko $V$ et al. (2006): The second Euro Heart Survey on acute coronary syndromes: characteristics, treatment, and outcome of patients with ACS in Europe and the Mediterranean Basin in 2004. 2 Eur Heart J., 27(19):2285-93.

4. Terkelsen CJ1, Lassen JF, Nørgaard BL et al. (2005): Reduction of treatment delay in patients with ST-elevation myocardial infarction: impact of pre-hospital diagnosis and direct referral to primary percutanous coronary intervention. Eur Heart J., 26(8):770-7.

5. Bassand JP (2007): Impact of anaemia, bleeding, and transfusions in acute coronary syndromes: a shift in the paradigm. Eur Heart J., 28(11): 1273-4.

6. Backus BE, Six AJ, Kelder JH et al. (2000): Risk scores for patients with chest pain: evaluation in the emergency department. Curr Cardiol Rev., 7(1):2-8. 
7. Bradshaw PJ1, Ko DT, Newman AM et al. (2006): Validity of the GRACE (Global Registry of Acute Coronary Events) acute coronary syndrome prediction model for six month post-discharge death in an independent data set. Heart, 92(7):905-9.

8. Eggers KM1, Kempf T, Venge P et al. (2010): Improving long-term risk prediction in patients with acute chest pain: the Global Registry of Acute Coronary Events (GRACE) risk score is enhanced by selected nonnecrosis biomarkers. Am Heart J., 160(1):88-94.

9. Aragam KG1, Tamhane UU, Kline-Rogers E et al. (2009): Does simplicity compromise accuracy in ACS risk prediction? A retrospective analysis of the TIMI and GRACE risk scores. PLoS One, 4(11):e7947.

10. Antman EM1, Cohen M, Bernink PJ et al. (2000): The TIMI risk score for unstable angina/non-ST elevation MI: a method for prognostication and therapeutic decision making. JAMA., 284(7):835-42.

11.Montorsi P1, Ravagnani PM, Galli S et al. (2006): Association between erectile dysfunction and coronary artery disease. Role of coronary clinical presentation and extent of coronary vessels involvement: The COBRA trial. Eur Heart J., 27(22):2632-9.
12.Santos ES, Luciano FA, Daniela MF et al. (2013): Correlation of risk scores with coronary anatomy in nonST-elevation acute coronary syndrome. Arq Bras Cardiol., 100(6): 511-517.

13. Iscanli MD, Aksu NM, Banu E et al. (2014): Comparison of TIMI and Gensini score in patients admitted to the emergency department with chest pain, who underwent coronary angiography. Med Sci Monit., 20: 343-9.

14. Mahmood M, Achakzai AS, Akhtar P et al. (2013): Comparison of the TIMI and the GRACE risk scores with the extent of coronary artery disease in patients with nonST-elevation acute coronary syndrome. J Pak Med Assoc., 63(6):691-5.

15. Khandelwal G, Jain A and Rathore M (2015): Prediction of Angiographic Extent of Coronary Artery Disease on the Basis of Clinical Risk Scores in Patients of Unstable Angina. J Clin Diagn Res., 9(11): 13-6.

16. Barbosa CE, Viana M, Brito $M$ et al. (2012): Accuracy of the GRACE and TIMI scores in predicting the angiographic severity of acute coronary syndrome. Arq Bras Cardiol., 99(3): 818-24. 